\title{
Effects of the Prolyl Endopeptidase Inhibitor S 17092 on Cognitive Deficits in Chronic Low Dose MPTP-Treated Monkeys
}

\author{
J. S. Schneider, Ph.D., M. Giardiniere, B.S., and P. Morain, Ph.D.
}

A number of neuropeptides are affected in Parkinson's disease and the enzyme proline endopeptidase contributes to the degradation of many of these neuropeptides, some of which are linked to a variety of cognitive functions. In the present study, the effects of the highly potent proline endopeptidase inhibitor $S 17092$ on cognitive deficits in monkeys induced by chronic low dose 1-methyl-4-phenyl1,2,3,6-tetrahydropyridine (MPTP) administration were examined. Chronic low dose MPTP administration resulted in deficits in performance of variable delayed response, delayed matching-to-sample, and delayed alternation tasks. Seven day oral administration of $S 17092$ followed by single dose administration of the same dose on the day of testing significantly improved overall performance on these tasks. The most effective dose of $S 17092$ was $3 \mathrm{mg} / \mathrm{kg}$. These results indicate that $S 17092$ has cognition-enhancing properties in this model of early parkinsonism.

[Neuropsychopharmacology 26:176-182, 2002] (C) 2002 American College of Neuropsychopharmacology. Published by Elsevier Science Inc.
KEY WORDS: Parkinsonism; Cognition; Neuropeptide; Proline endopeptidase

It is generally recognized that non-demented Parkinson's disease (PD) patients exhibit a number of neuropsychological deficits, some of which are present even at the earliest stages of the disease (Lees and Smith 1983; Levin et al. 1989; Owen et al. 1993). Many of these deficits are 'frontal-like' in nature and consist of problems in attentional set shifting (Owen et al. 1993), distractibility (Sharpe 1990) planning and 'executive functions' (Morris

From the Department of Pathology, Anatomy, and Cell Biology, Thomas Jefferson University, 1020 Locust Street, Philadelphia, PA (JSS, MG), Institut de Recherches Internationales Servier, Courbevoie, France (PM)

Address correspondence to: Dr. J. S. Schneider, Department of Pathology, Anatomy and Cell Biology, Thomas Jefferson University, 1020 Locust Street, Room 521 JAH, Philadelphia, PA 19107, Tel.:

215-503-0370, Fax: 215-923-3808, E-mail: jay.schneider@mail.tju.edu

Received February 28, 2001; revised May 22, 2001; accepted June $15,2001$.

Online publication: 6/15/01 at www.acnp.org/citations/Npp 061601139. et al. 1988) and spatial working memory (Owen et al. 1992). Parkinson's disease patients also may have difficulty performing a delayed matching-to-sample shortterm visual recognition memory task, but their problems appear more related to attentional difficulties rather than to visual recognition memory problems (Lange et al. 1992).

The neurochemical deficits underlying the cognitive disturbances in PD patients are not completely known. While most of the motor symptoms of PD can be related to a nigrostriatal dopaminergic defect, the relationship between the dopaminergic defect and cognitive deficits in PD is less clear. Some cognitive deficits in PD may be dopa-responsive but others are not (Cooper et al. 1992; Lange et al. 1992). Some cognitive problems in PD patients are even exacerbated by dopaminergic therapy (Gotham et al. 1988). These findings suggest that the cognitive deficits in PD patients most likely arise from dysfunction of several cortical and subcortical neurotransmitter systems and functional circuits that cannot be normalized by dopamine replacement therapy alone. This is supported by the recent finding that a 
sub-type specific neuronal nicotinic acetylcholine receptor agonist, but not levodopa, was able to improve cognitive functioning in dopamine lesioned monkeys (Schneider et al. 1999). The nicotinic receptor agonist effects on cognition were most likely related to the ability of this compound to release dopamine from striatal, limbic and frontal cortical sites, norepinephrine from hippocampal, thalamic and frontal cortical sites and acetylcholine from various cortical and subcortical sites (Menzaghi et al. 1996; Sacaan et al. 1997).

In addition to deficits in levels of various neurotransmitters in PD and in animal models of PD, decreased levels of various neuropeptides may also contribute to parkinsonian symptomatology (Mauborgne et al. 1983). Several neuropeptides, particularly substance $P$, have been implicated in learning and memory (Huston and Hasenohrl 1995) and are present endogenously in cortex and striatum. Substance P levels are also depleted in the striatum of monkeys made parkinsonian by exposure to the neurotoxin 1-methyl-4-phenyl-1,2,3,6-tetrahydropyridine (MPTP). Since proline-containing neuropeptides such as substance $P$. vasopressin and thyrotropin-releasing hormone have all been implicated as potential cognition enhancers (Toide et al. 1995), a possible therapeutic approach to the cognitive deficits associated with parkinsonism might be enhancement of endogenous neuropeptide levels. This could be accomplished through protection of neuropeptides from degradation with peptidase inhibitors.

Proline endopeptidase is a serine endooligopeptidase involved in the degradation of various neuropeptides in vitro and in vivo (Checler 1993). S 17092 is a highly potent, orally active, cell permeant inhibitor of proline endopeptidase in brain (Barelli et al. 1999; Lepagnol et al. 1996). S 17092 can at least partially reverse scopolamine-induced amnesia and age-associated spatial delayed alternation deficits in mice, as well as increase striatal substance $\mathrm{P}$ immunoreactivity (Lestage et al. 1998). The present study aimed to assess the extent to which S 17092 might improve cognition in chronic low dose MPTP-treated monkeys, a model of early-stage parkinsonism previously shown to exhibit cognitive deficits similar to those detected in PD patients (Schneider and Kovelowski 1990; Schneider and Roeltgen 1993).

\section{MATERIALS AND METHODS}

Four adult male Macaca fascicularis monkeys (5 to $7 \mathrm{~kg}$ ) were trained to perform variable delayed response (VDR), delayed alternation (DA), delayed matching-to-sample (DMS) and visual discrimination tasks. One additional adult male $\mathrm{M}$. fascicularis monkey performed only the VDR task. All monkeys performed tasks while seated inside a modified Wisconsin General Test Apparatus
(Schneider and Kovelowski 1990). Prior to the start of training, all monkeys were adapted to chair restraint and the experimental set-up. Monkeys were food deprived overnight prior to testing. All procedures were carried out in accordance with the Guide for the Care and Use of Laboratory Animals as adopted by the National Institutes of Health and were approved by the Thomas Jefferson University Institutional Animal Care and Use Committee.

\section{Variable Delayed Response (VDR)}

The monkeys sat in a restraining chair situated in a sound-attenuating chamber with background masking noise, behind an opaque screen that when raised, allowed access to a sliding tray. The tray contained recessed food wells and identical sliding red Plexiglas covers that served as stimulus plaques that could be displaced by the animal to obtain rewards (raisins, dried fruit). The monkeys were trained to retrieve food from one of the wells after observing the experimenter bait a well. Right and left wells were baited in a balanced order. For all animals performing the VDR task, five different delay lengths were randomly distributed in blocks of trials over the 40 trials that made up a daily testing session. In two animals, the range of delays were 2 to 30 seconds; two animals had the longest delay set at 45 seconds; one animal had the longest delay set at $60 \mathrm{sec}-$ onds. These conditions yielded approximately chance performance at the longest delays.

\section{Delayed Matching-to-Sample Testing (DMS)}

On DMS trials, the monkey was shown a colored Plexiglas cover in the center of the sliding response panel that served as the cue or sample for the subsequent match. Following cue presentation, a 5-sec delay was imposed after which the monkey was given the choice of responding to the same colored cover that was used as the cue or to an adjacent cover of another color. Displacement of the same colored cover as used for the cue allowed access to a food reward. Each daily session consisted of 30 trials and animals were trained to perform at approximately a $90 \%$ criterion level.

\section{Delayed Alternation}

On each trial, monkeys were presented with two identical covers over recessed food wells and were required to alternate responses between left and right wells on successive trials separated by a 5-sec inter-trial delay. A non-correction procedure was used so that if an error was made on any given trial, the reward would remain on the same side until a correct response was made. Animals were trained to perform at approximately a $90 \%$ criterion level on 30 trials per day. 


\section{Visual Pattern Discrimination}

For visual discrimination testing, monkeys were trained to discriminate between two patterns (a cross and a horizontal bar) on otherwise identical white Plexiglas covers. The positive stimulus (cross) appeared on a cover over the left or right food wells in a balanced order. The cover had to be displaced in order to retrieve reward from the recessed food well beneath the cover. A session consisted of 30 trials and the monkey was trained to a $90 \%$ correct criterion level.

\section{Drug Administration}

Once animals achieved stable baseline task performance, MPTP administration began. MPTP-HCl (RBI, Natick, MA) was administered intravenously two to three times per week while animals were seated in a restraining chair, as described previously (Schneider and Kovelowski 1990). Adequate precautions were taken to protect personnel from exposure to MPTP during injections and from any possible unmetabolized MPTP in animal excreta (Schneider and Roeltgen 1993). MPTP was administered at a dose of $0.075 \mathrm{mg} / \mathrm{kg}$ per injection. By the time drug testing commenced, animals had received total amounts of MPTP ranging between 0.38 and $4.8 \mathrm{mg}$ over periods of 27 to 63 days. The different total amounts of MPTP administered reflect individual animal variability in response to the toxin. Although different total amounts of MPTP were administered to different animals for different periods of time, the nature of the cognitive deficits were the same in all the animals. Pharmacological testing commenced after animals consistently showed at least $15 \%$ performance deficit on each task known to be sensitive to MPTP exposure (Schneider and Kovelowski 1990; Schneider and Roeltgen 1993) for approximately two months.

S 17092 powder was mixed with 3 to 5 drops of Tween 20 and added to 10 to $20 \mathrm{ml}$ of fruit-flavored drink. Drug was prepared immediately prior to use and administered orally to monkeys in their home cages. S 17092 was administered for seven days prior to formal testing of drug effects on cognitive task performance. On the day of testing, the same dose of S 17092 that was administered during the preceding 7-day dosing period was given to the animals and cognitive performance was assessed beginning approximately $30 \mathrm{~min}$ after drug administration. Because monkeys occasionally would not perform all of the tests in one day, task performance was usually assessed over two consecutive days of administration of the test dose of S 17092. Based on existing literature (Lepagnol et al. 1996; Lestage et al. 1998), the drug doses used were 1.0, 3.0 and $10.0 \mathrm{mg} / \mathrm{kg}$. Different doses were administered in quasi-random order. There was at least two weeks of washout prior to starting the next 7-day dosing regimen with a new dose of drug. Cognitive performance was assessed at the end of the washout period to insure that deficits were consistent with those observed during the post-MPTP baseline period prior to starting the evaluation of a new drug dose. Each dose of S 17092 was assessed twice and performance was compared to non-drug performance during washout days prior to and after drug testing.

\section{Data Analysis}

Each dose of each drug was tested twice and the data were pooled for statistical analysis. Task performance on drug was compared with matched control performance (non-drug). Animals served as their own controls and thus statistical analyses employed repeated measures designs: one way analysis of variance (ANOVA) on all drug doses with pairwise post hoc comparisons (paired t-test, Newman-Keuls test) of baseline (non-drug) and drug performance.

\section{RESULTS}

\section{Effects of MPTP Exposure on Cognitive Task Performance}

Prior to initiation of MPTP exposure, the animals had a mean baseline performance of $81.2 \%$ correct responses $( \pm 1.6)$ on the VDR task. There was a significant effect of delay on task performance such that all monkeys performed well on short delay trials but performance deteriorated to almost chance performance at the longer delays (Figure 1). In normal animals performance at shorter duration delays (i.e., 2, 5 and $10 \mathrm{sec}$ ) differed significantly from performance at longer duration delays $(20,30,45$ or 60 sec, F $(6,133)=18.2, p<.0001)$. Shortduration delay trials $(2,5$ and $10 \mathrm{sec})$ were performed at $93.3 \% \pm 2.4,89.7 \% \pm 3.2$ and $88.8 \% \pm 2.5$ correct, respectively. Normal performance declined with increasingly long delay durations (20-sec delay: $71.1 \% \pm 3.5$; 30-sec delay: $67.0 \% \pm 2.4 ; 45$-sec delay: $59.3 \% \pm 4.3 ; 60-$ sec delay: $62.8 \% \pm 3.9$.

After chronic MPTP exposure, overall performance on the VDR task deteriorated to $60.9 \%$ correct responses $( \pm 2.3)(t=35.7, p<.01)$. In contrast to the normal performance of this task, monkeys exhibited a delay-independent performance deficit after chronic exposure to MPTP. That is, monkeys were now almost as likely to perform poorly on 2, 5 or 10 -sec delay trials $(68.6 \%$ correct responses $\pm 3.1,70.9 \% \pm 3.2$, and $62.7 \% \pm 3.5$, respectively) as on $20-\sec (54.7 \% \pm 3.8), 30-\sec (63.3 \% \pm$ $3.5), 45-\sec (53.9 \% \pm 4.2)$ or $60-\sec (53.9 \% \pm 5.2)$ delay trials (Figure 1). The effect of MPTP exposure on performance at different delays was significant $(\mathrm{F}(6,132)=$ $3.5, p=.0029)$. Pairwise post hoc comparisons showed that performance at 2, 5, 10 and 20-sec delays changed significantly after MPTP exposure $(\mathrm{t}=30.2, p<.01, \mathrm{t}=$ 


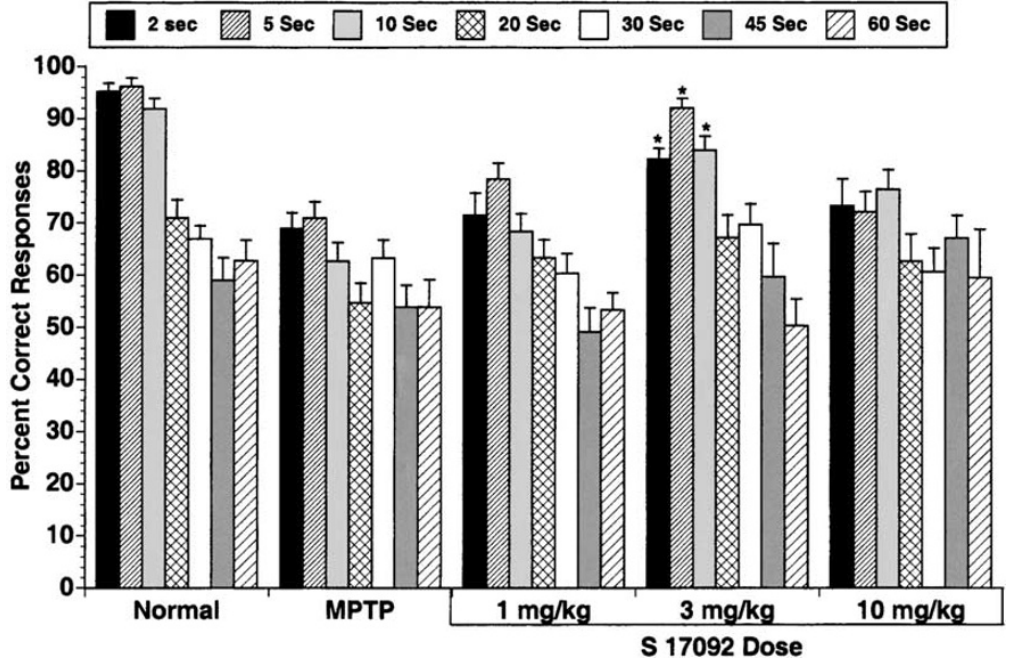

Figure 1. Prior to MPTP exposure, all animals displayed a delay-dependent decrease in performance on the variable delayed response task $(n=5)$. After MPTP exposure, trials at all delays were performed poorly. The $3.0 \mathrm{mg} / \mathrm{kg}$ dose of S 17092, after a 7-day exposure to the drug, caused a significant improvement in performance of 2, 5, and 10 -sec delay trials. Graphs show means \pm SEM. ${ }^{*}<.01$ vs. non-drug control trials.
17.6, $p<.01, \mathrm{t}=33.7, p<.01, \mathrm{t}=13.3, p<.05$, respectively ) while performance at 30, 45 and 60-sec delays $(\mathrm{t}=$ $0.6, p>05, \mathrm{t}=0.9, p>0.05, \mathrm{t}=0.9, p>.05$, respectively) was unaffected by the MPTP exposure.

Prior to MPTP administration, the DMS task was performed at a level of $94.4 \%$ correct responses $( \pm 1.2)$. After chronic MPTP exposure, performance deteriorated to $62.2 \%$ correct responses $( \pm 1.8)(\mathrm{t}=124.0, p<$ $.01)$ (Figure 2). The DA task was performed at a level of 93.5\% correct responses $( \pm 1.2$ ) before MPTP exposure. After chronic MPTP administration, performance deteriorated to $76.2 \%$ correct responses $( \pm 2.6)(\mathrm{t}=28.3, p<$
.01) (Figure 3). Prior to receiving any MPTP, VD performance was $95.9 \%$ correct $( \pm 1.1)$ and task performance remained intact after chronic MPTP exposure $(95.5 \%$ correct responses \pm 1.0 ) and was not affected by $\mathrm{S} 17092$ administration (data not shown).

\section{Effects of S 17092 on VDR, DMS, DA and VD Performance in Chronic Low Dose MPTP-Treated Monkeys}

S 17092 caused a dose-dependent improvement in performance of the VDR task (Figure 1). S 17092 signifi-

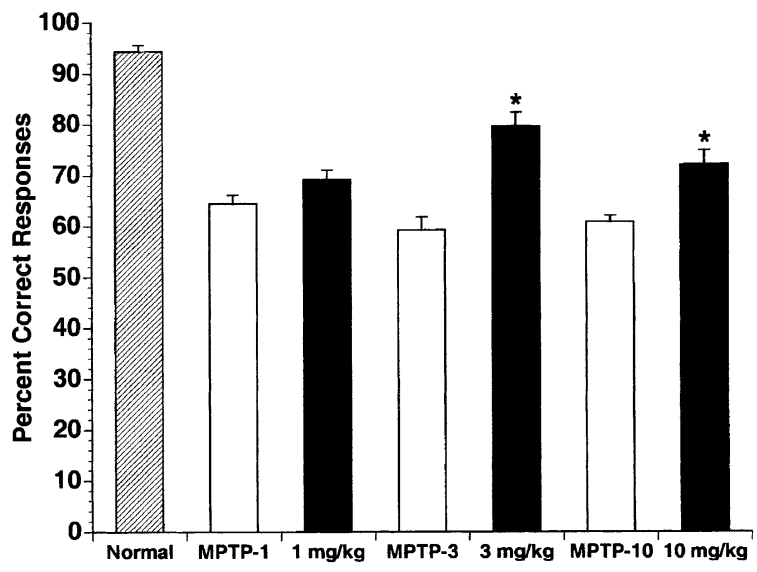

Figure 2. Performance of the delayed matching-to-sample task was significantly impaired after MPTP exposure. Administration of S 17092 significantly improved DMS performance at both 3.0 and $10.0 \mathrm{mg} / \mathrm{kg}$ doses, following seven days of drug administration. Graphs show means \pm SEM. ${ }^{*} p<.01$ vs. non-drug control trials. MPTP-1 = control trials associated with testing of $1 \mathrm{mg} / \mathrm{kg} \mathrm{S} \mathrm{17092;} \mathrm{MPTP-3} \mathrm{=}$ control trials associated with testing $3 \mathrm{mg} / \mathrm{kg} \mathrm{S} \mathrm{17092;}$ MPTP-10 $=$ control trials associated with testing of $10 \mathrm{mg} /$ $\operatorname{kg~S~} 17092$.

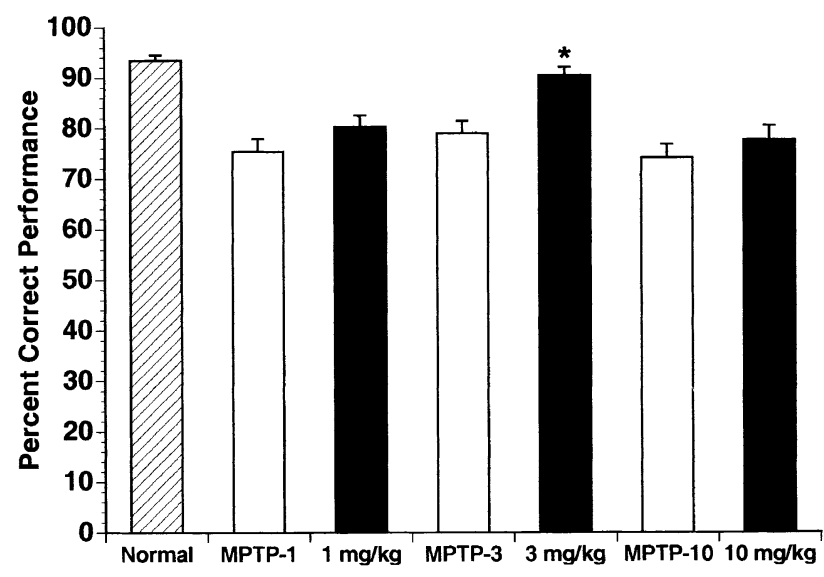

Figure 3. Performance of the delayed alternation task was significantly impaired after MPTP exposure. Administration of S 17092 significantly improved DA performance at the 3.0 $\mathrm{mg} / \mathrm{kg}$ doses, after a 7-day exposure to the drug. Graphs show means \pm SEM. ${ }^{*} p<.01$ vs. non-drug control trials. MPTP-1 = control trials associated with testing of $1 \mathrm{mg} / \mathrm{kg} \mathrm{S}$ 17092; MPTP-3 = control trials associated with testing of $3 \mathrm{mg} / \mathrm{kg} \mathrm{S} \mathrm{17092;} \mathrm{MPTP-10} \mathrm{=} \mathrm{control} \mathrm{trials} \mathrm{associated} \mathrm{with}$ testing of $10 \mathrm{mg} / \mathrm{kg} \mathrm{S} 17092$. 
cantly improved VDR performance at the $3.0 \mathrm{mg} / \mathrm{kg}$ dose $(76.9 \%$ correct $\pm 2.0, \mathrm{t}=29.2, p<.01$ vs. non-drug post-MPTP performance) but not at 1.0 or $10.0 \mathrm{mg} / \mathrm{kg}$ doses. After administration of $3.0 \mathrm{mg} / \mathrm{kg} \mathrm{S} \mathrm{17092,} \mathrm{VDR}$ performance tended to revert back to a normal delaydependent pattern. At the $3.0 \mathrm{mg} / \mathrm{kg}$ dose, performance significantly improved on shorter delay trials (2, 5 , and $10 \mathrm{sec}, \mathrm{t}=7.2, p<.05, \mathrm{t}=16.8, p<.01, \mathrm{t}=24.5$, $p<.01$, respectively) but not on longer delay trials (20, 30,45 and $60 \mathrm{sec}$ ). Improved performance on shorter delay trials was not seen with either the 1.0 or $10.0 \mathrm{mg} / \mathrm{kg}$ doses.

Significant improvements in DMS performance were also observed after S 17092 administration $(F(6,109)=$ $34.9, p<.0001)$ (Figure 2). On this task, improvements were seen with the $3.0 \mathrm{mg} / \mathrm{kg}$ dose $(\mathrm{t}=35.9, p<.01)$ as well as with the $10 \mathrm{mg} / \mathrm{kg}$ dose $(\mathrm{t}=17.2, p<.01)$. The $1.0 \mathrm{mg} / \mathrm{kg}$ dose had no effects on DMS performance. With the $3.0 \mathrm{mg} / \mathrm{kg}$ dose, performance went from $59.3 \% \pm 2.6$ to $79.7 \% \pm 2.7$. The $10.0 \mathrm{mg} / \mathrm{kg}$ dose caused performance to improve from $60.9 \% \pm 1.3$ to $72.2 \% \pm 2.8$.

S 17092 administration also improved DA performance, but only at the $3.0 \mathrm{mg} / \mathrm{kg}$ dose $(\mathrm{t}=12.6, p<$ .01) (Figure 3). Performance went from $79.0 \% \pm 2.5$ to $90.6 \% \pm 1.6$.

\section{DISCUSSION}

The prolyl endopeptidase inhibitor S 17092, administered orally to chronic low dose MPTP-treated monkeys with significant cognitive impairments, improved performance of cognitive tasks (VDR, DMS, DA). The normal performance of these tasks are usually associated with the functional integrity of fronto-striatal circuits. The function of these circuits appear to be impaired in both PD and in the chronic low dose MPTP model of parkinsonism. In MPTP-treated monkeys there is at least partial improvement of these functions after administration of $S 17092$.

In the present studies, the most efficacious dose of $S$ 17092 was $3.0 \mathrm{mg} / \mathrm{kg}$. The $1.0 \mathrm{mg} / \mathrm{kg}$ dose was ineffective in all tests whereas the $10.0 \mathrm{mg} / \mathrm{kg}$ dose significantly improved only DMS performance. The reasons for this high dose effect on performance of this particular task are unclear. S 17092 did not significantly improve performance on long duration delay trials $(\geqslant 20$ $\mathrm{sec}$ ) in the VDR task. Interestingly, the normal limit of working memory in these monkeys was approximately $10 \mathrm{sec}$. That is, under normal conditions, task performance significantly deteriorated with delays of $20 \mathrm{sec}$ or greater. Thus S 17092 appeared to improve memory within its normal limits in these animals and may also have enhanced attentional abilities (evidenced by improved performance at short duration delays). The present studies however were not designed to separate out attentional from memory effects on task performance and additional work is necessary to determine if there are preferential effects of S 17092 on attention or memory functions.

Chronic oral pre-treatment with S 17092 for seven days prior to administration of the test dose of drug and cognitive testing was necessary in order to observe cognition-enhancing effects. During the first three days of the 7-day pre-treatment period, S 17092 did not improve any of the cognitive functions measured (data not shown). These data are consistent with previous reports that showed chronic oral administration of $S$ 17092 to be more effective than acute administration in increasing striatal substance P-like immunoreactivity (Lestage et al. 1998). In other studies, chronic administration of S 17092 inhibited brain post-proline cleaving enzyme activity by more than $50 \%$ and improved learning and memory performances in both young scopolamine-treated and aged mice (Lestage et al. 1998). Although this was not directly assessed in the current studies, these findings suggest that cognition enhancing properties of S 17092 may be related to enhanced neuropeptide activities in the brain.

A number of neuropeptides, including substance $P$ are decreased in PD and in patients with Alzheimer's type dementia (Husain and Nemeroff 1990). In particular, tritiated substance P binding and substance P-like immunoreactivity have been reported to be significantly reduced in the parietal cortex and nucleus basalis of Meynert as well as in the substantia nigra and internal globus pallidus in PD brain (Tenovuo et al. 1990). The neurochemical deficits underlying the cognitive dysfunctions in chronic MPTP-treated monkeys and the status of brain neuropeptides in these animals are unknown. Levels of a variety of neuropeptides were unaltered in monkeys acutely administered MPTP (Zamir et al. 1984). Recent pharmacological studies have shown that dopamine replacement therapy (using levodopa) was ineffective in substantially reversing the cognitive deficits in chronic low dose MPTP-treated monkeys while treatment with neuronal nicotinic acetylcholine receptor (nAChR) agonists (Schneider et al. 1999) or the partial glycine agonist D-cyloserine (Schneider et al. 2000) significantly improved performance on a variety of cognitive tasks. The cognitive deficits in chronic low dose MPTP-treated monkeys and in PD patients most likely arise from dysfunction of several cortical and subcortical neurotransmitter systems and functional circuits, such that L-dopa treatment alone cannot sufficiently normalize behavior. The superior effects of nAChR agonists, D-cycloserine and proline-endopeptidase inhibitors may be due to the ability of these drugs to modulate release of dopamine and other neurotransmitters including norepinephrine and acetylcholine from various cortical and subcortical sites. It is well known that neuropeptides can modulate the activity of 
dopamine as well as other neurotransmitters such as acetylcholine. In particular, cholinergic neurotransmission is facilitated by substance P (Lestage et al. 1998). Proline endopeptidase inhibitors may improve cognitive function in MPTP-treated monkeys by indirectly promoting functions of a variety of neurotransmitter systems and/or by direct neuropeptide effects in the basal ganglia and other subcortical and cortical regions. These mechanisms alone or in combination may contribute to the effectiveness of S 17092 as a potential cognition enhancing agent in PD. A similar mechanism (i.e., promoting functions of a variety of neurotransmitter systems) was previously proposed to explain the beneficial effects of a nicotinic acetylcholine receptor agonist as well as the lack of effect of levodopa on the same behaviors assessed in this study (Schneider et al. 1999).

In summary, the proline endopeptidase inhibitor $S$ 17092 improves cognitive task performance in chronic low dose MPTP-treated monkeys and seems to have potential benefit as a treatment for at least some of the cognitive disorders associated with parkinsonism.

\section{ACKNOWLEDGMENTS}

This research was supported by the Institut de Recherches Internationales Servier. Dr. Schneider has been a paid consultant of the Institut de Recherches Internationales Servier and does not currently have a financial or other involvement with this organization. Dr. Morain is an employee of the Institut de Recherches Internationales Servier.

\section{REFERENCES}

Barelli H, Petit A, Hirsch E, Wilk S, De Nanteuil G, Morain P, Checler F (1999): S 17092, a highly potent, specific and cell permeant inhibitor of human proline endopeptidase. Biochem Biophys Res Commun 257:657-661

Checler F (1993): Neuropeptide-degrading peptidase. In Parvez SH, Naoi M, Nagatsu T, Parvez S. (eds), Methods in Neurotransmitter and Neuropeptide Research, Part 2. Amsterdam, Elsevier, pp 375-418

Cooper JA, Sagar HJ, Doherty SM, Jordan N, Tidswell P, Sullivan EV (1992): Different effects of dopaminergic and anticholinergic therapies on cognitive and motor function in Parkinson's disease. Brain 115:1701-1725

Gotham AM, Brown RG, Marsden CD (1988): 'Frontal' cognitive function in patients with Parkinson's disease 'on' and 'off' levodopa. Brain 111:299-321

Husain MM, Nemeroff CB (1990): Neuropeptides and Alzheimer's disease. J Am Geriatr Soc 38:918-9125

Huston JP, Hasenohrl RU (1995): The role of neuropeptides in learning: focus on the neurokinin substance P. Behav Brain Res 66:117-127

Lange KW, Robbins TW, Marsden CD, James M, Owen AM, Paul GM (1992): L-dopa withdrawal in Parkinson's disease selectively impairs cognitive performance in tests sensitive to frontal lobe dysfunction. Psychopharmacol 107:394-404

Lees AJ, Smith E (1983): Cognitive deficits in the early stages of Parkinson's disease. Brain 106:257-270

Lepagnol J, Lebrun C, Morain P, De Nateuil G, Heidet V (1996): Cognition enhancing effects of S 17092, a potent inhibitor of post-proline cleaving enzyme (PPCE). Soc Neurosci Abstr 22:142

Lestage P, Lebrun C, Iop F, Hugot A, Rogez N, Greve P, Favale D, Gandon M-H, Raimbault O, Lepagnol J (1998): S 17092, a new post-proline cleaving enzyme inhibitor: memory enhancing effects and substance $P$ neuromodulatory activity. Adv Behav Biol 49:653-660

Levin BE, Llabre MM, Weiner WJ (1989) Cognitive impairments associated with early Parkinson's disease. Neurology 39:557-561

Mauborgne A, Javoy-Agid F, Legrand JC, Agid Y, Cesselin F (1983): Decrease in substance P-like immunoreactivity in the substantia nigra and pallidum in Parkinsonian brains. Brain Res. 268:167-170

Menzaghi F, Sacaan AI, Reid RT, Santori EM, Correa LD, Adams P, Whelan KT, Risbrough VB, Rao TS, Schneider JS, Lloyd GK (1996): Characterization of SIB-1508Y, the active enantiomer of a novel nicotinic acetylcholine receptor (NAChR) agonist, SIB-1765F. Soc Neurosci Abstr 22:1523

Morris RG, Downes JJ, Sahakian BJ, Evenden JL, Heald A, Robbins TW (1988): Planning and spatial working memory in Parkinson's disease. J Neurol Neurosurg Psychiatr 51:757-766

Owen AM, Beksinka M, James M, Leigh PN, Summers BA, Marsden CD, Quinn NP, Sahakian BJ, Robbins TW (1993): Visuo-spatial memory deficits at different stages of Parkinson's disease. Neuropsychologia 31:627-644

Owen AM, James M, Leigh PN, Summers BA, Marsden CD, Quinn NP, Lange KW, Robbins TW (1992): Fronto-striatal cognitive deficits at different stages of Parkinson's disease. Brain 115:1727-1751

Sacaan AI, Santori EM, Keegan M, Lloyd GK, Rao TS (1997): Dopamine (DA) and norepinephrine (NE) release in the prefrontal cortex (PFC) are regulated by different nAChR subtypes. Soc Neurosci Abstr 22:1523

Schneider JS, Kovelowski CJ (1990): Chronic exposure to low doses of MPTP. I. Cognitive deficits in motor asymptomatic monkeys. Brain Res 519:122-128

Schneider JS, Roeltgen DP (1993): Delayed matching-to-sample, object retrieval, and discrimination reversal deficits in chronic low dose MPTP-treated monkeys, Brain Res 615:351-354

Schneider JS, Tinker JP, Van Velson M, Giardiniere M (2000): Effects of the partial glycine agonist D-cycloserine on cognitive functioning in chronic low dose MPTP-treated monkeys. Brain Res 860:190-194

Schneider JS, Tinker JP, Van Velson M, Menzaghi F, Lloyd GK (1999): Nicotinic acetylcholine receptor agonist SIB-1508Y improves cognitive functioning in chronic low dose MPTPtreated monkeys. J Pharmacol Exp Ther 290:731-739

Sharpe MH (1990): Distractibility in early Parkinson's disease. Cortex 26:239-246

Tenovuo O, Kolhinen O, Laihinen A, Rinne UK (1990): Brain substance P receptors in Parkinson's disease. In Streifler 
MB, Korczyn AD, Melamed E, Youdim MBH (eds), Advances in Neurology, Vol. 53, Parkinson's Disease: Anatomy, Pathology, and Therapy. New York, Raven Press, pp 145-148

Toide K, Iwamoto Y, Fujiwara T, Abe H (1995): JTP-4819: A novel prolyl endopeptidase inhibitor with potential as a cognitive enhancer. J Pharmacol Exp Ther 274:13701378

Zamir N, Skofitsch G, Bannon MJ, Helke CJ, Kopin IJ, Jacobowitz DM (1984): Primate model of Parkinson's disease: alterations in multiple opioid systems in the basal ganglia. Brain Res 322:356-360 